\title{
THE EFFECTS OF MULTILAYER POROUS MEDIA ON THE EFFICIENCY OF FILTRATION COMBUSTION
}

\author{
Artem Lavrentev, Ali Tarokh* \\ Department of Mechanical Engineering, Lakehead University, Thunder Bay, Canada. \\ *Corresponding Author: atarokh@lakeheadu.ca
}

\begin{abstract}
Diffusion filtration combustion in a radiative jet burner is numerically investigated. This study focuses on the effects of the porous media structure on the efficiency of nonpremixed combustion, namely combustion temperature and NOx emissions. For this investigation, methane-air combustion within a two-layer porous media is considered. Twodimensional axisymmetric model is chosen to reduce the number of elements and the corresponding computational resource requirements. Fluid turbulence is resolved using the k$\omega$ SST turbulence model, while the turbulence-controlled reaction rates are computed using the eddy dissipation model. Stoichiometric, two-step methane-air reaction is utilized in the reaction zone. In the present model both thermal and prompt NOx formation mechanisms are considered, where an extended Zeldovich mechanism is used for thermal NOx formation. For high combustion temperatures where radiative heat flux is larger than that of convection and conduction heat transfer rates, radiation becomes the dominant heat transfer mode. To account for the emission and scattering of thermal radiation by the porous media, the Discrete Ordinate model is considered. The relationship between velocity and pressure corrections is calculated using the SIMPLE algorithm. The layered porous zone arrangement is utilized to increase combustion performance due to enhanced fuel-air mixing through increased heat recirculation within the multilayer porous media. Utilizing two layers of equal height, $\varepsilon=0.6$ and 0.45 , upstream and downstream, respectively increased combustion temperature while decreasing combustion zone and NOx emission. Additionally, the effects of the thickness of each layer on combustion efficiency are studied. Increasing the height of the low porosity downstream region, which effectively decreases the height of the upstream high porosity region, resulted in increased NOx emissions due to higher temperature in the combustion zone.
\end{abstract}

Keywords- non-premixed, diffusion filtration combustion, methane-air combustion, porous media

\section{INTRODUCTION}

Combustion phenomena is intrinsic to the energy systems currently in place, forever evolving and becoming increasingly sophisticated as considerable research has been and is being conducted on the topic. The research outcomes catalyze the innovation of combustion systems through novel concepts and theories. One of such outcomes is porous media combustion, also known as filtration combustion.

Based on the idea of using a highly thermally conductive solid matrix as a means of heat recirculation within the system, earliest works believed to be attributed to Takeno and Sato [1], porous media combustion (PMC) has been shown to have a multitude of advantages. PMC studies based on using premixed and non-premixed reactants, the former subjected to more extensive research [2]-[7] have shown lower pollutant emissions due to lower combustion temperature, higher flame stability and system scalability, to name a few. To date, non-premixed combustion or diffusion filtration combustion (DFC), which utilizes turbulent non-premixed (diffusion) and premixed filtration combustion, falls short in the literature availability as compared to that of its counterpart.

Early works such as that of Kamiuto and Ogawa [8], focused on diffusion flame characteristics using a flame sheet model and experimented with methane-air diffusion in a cylindrical bed packed with alumina spheres. Dobrego et al. [9] used a twodimensional, two temperature model to analyze methane-air DFC and found a (200-300 K) temperature difference between solid and gas, which is higher than the difference found in premixed combustion. One of the issues with using a porous solid for combustion is the deceleration of fuel-air mixing which influences reaction completion. To mitigate this Kamal and Mohamad [10] introduced a high degree of swirl and a reported 5.7 times improvement in radiation flux, with decrease in $\mathrm{CO}$ and NOx emissions.

Zhang et al. [11] utilized DFC for a porous inserted regenerative thermal oxidizer system in an industrial coppermelting furnace. Using a one-temperature model it was found that the system achieved a significant reduction in the NOx emission level and a fuel saving of approximately 30\% compared to a typical regenerative thermal oxidizer. Kostenko et al. [12] numerically examined methane to synthesis gas 
conversion in DFC within a reversed flow bed reactor using a kinetic model. Comparison between premixed and nonpremixed showed that a higher combustion temperature was attained in the non-premixed case.

Shi et al. [13] studied DFC characteristics, based on twodimensional numerical investigations on a plate-parallel diffusion filtration combustor with different packed bed heights. Their results showed a significant temperature decrease with a bed height increase from $40 \mathrm{~mm}$ to $80 \mathrm{~mm}$, as well as, the existence of two types of flame, immersed and surface, with two luminous zones between $40 \mathrm{~mm} \leq h \leq 160 \mathrm{~mm}$. Immersed packed bed flame characteristics were found to exhibit the outcome that of diffusion combustion, but experimental measurements showed wider high temperature zone and temperature distribution contradicted diffusion combustion characteristics. In a subsequent study Shi et al [14] conducted experimental and numerical study on DFC using a porous combustor with varying alumina pellet diameters, 2.5 and $3.5 \mathrm{~mm}$. Results showed a coexisting immersed and surface flame within the combustor exhibiting diffusion combustion characteristics. The immersed flame was seen to increase in h while surface flame decreased. NO emission decreased more with increase in h up to $120 \mathrm{~mm}$ and less with further height increase.

The aim of this study is to investigate the effect of doublelayered porous media arrangement on diffusion filtration combustion characteristics. Starting with a packed bed of $\varepsilon=0.6$ another layer of $\varepsilon=0.45$ is added downstream within the PM and the height of each layer is varied. Focus is directed towards the effect of double layer porous media height variation on reactant mixing and consequent combustion temperature and NOx emission.

\section{MODELLING AND NUMERICAL SIMULATION}

The computational domain considered is a porous cylindrical burner, as shown in Figure 1, with $50 \mathrm{~mm}$ diameter and $300 \mathrm{~mm}$ height. Methane is injected into a PM of diameter $50 \mathrm{~mm}$ and height $150 \mathrm{~mm}$ through a $20 \mathrm{~mm}$ nozzle, while air is injected through the annulus. The PM is a packed bed of $2 \mathrm{~mm}$ diameter alumina $\left(\mathrm{Al}_{2} \mathrm{O}_{3}\right)$ spheres, of varying porosity, $\varepsilon=0.6$ and 0.45 . Steady, incompressible, and Newtonian flow is considered.

The governing Navier-Stokes equations are solved with the finite volume method using FLUENT 19.2. Due to burner symmetry and to reduce the overall number of elements with corresponding computational resources a two-dimensional axisymmetric model is considered. The simulations are performed using double precision segregated implicit solver while the relationship between velocity and pressure corrections are calculated using the SIMPLE algorithm. Alumina spheres are modeled using coupled thermal boundary condition between the body and respective circular wall. Since the flow disturbance within the porous media is of interest, especially flow disturbance near the walls, $\mathrm{k}-\omega$ SST turbulence model is used. Turbulence controlled reaction rates are computed using the eddy dissipation model. Stoichiometric,

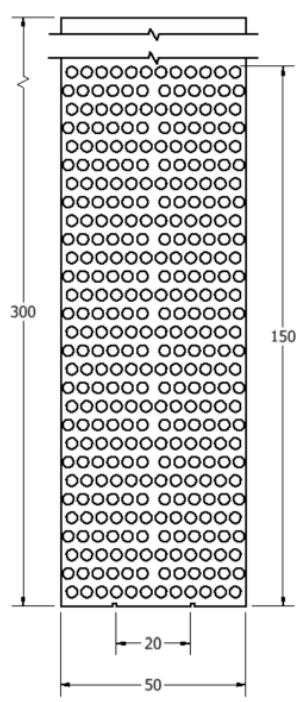

(a)

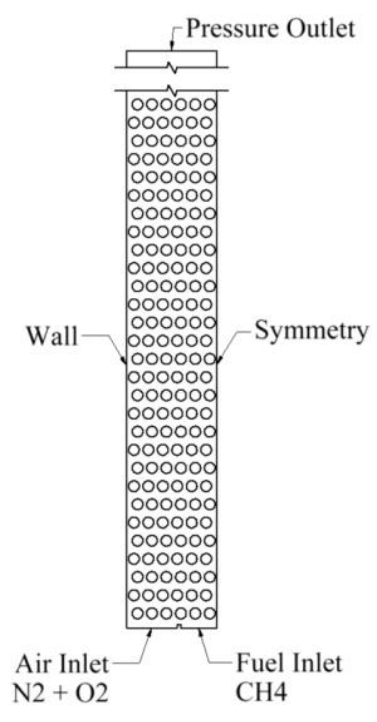

(b)
Figure 1. Burner dimensions (a) and Boundary conditions (b)

two-step methane-air reaction is utilized in the reaction zone. Fuel and air inlet are velocity inlets with equal velocity $v=0.01$ $\mathrm{m} / \mathrm{s}$. Outer wall is assumed to be adiabatic and outlet is set as pressure outlet. Residuals for the energy equation are taken to $10^{-6}$ while all other equations to $10^{-3}$.

\section{GOVERNING EQUATIONS}

The governing equations for the outlined model are as follows.

A. Navier-Stokes

Continuity:

$$
\frac{\partial \rho}{\partial x}\left(\rho v_{x}\right)+\frac{\partial \rho}{\partial r}\left(\rho v_{r}\right)+\frac{\rho v_{r}}{r}=S_{m}
$$

Axial momentum:

$$
\begin{array}{r}
\frac{1}{r} \frac{\partial}{\partial x}\left(r \rho v_{x} v_{x}\right)+\frac{1}{r} \frac{\partial}{\partial r}\left(r \rho v_{r} v_{x}\right)= \\
\frac{\partial p}{\partial x}+\frac{1}{r} \frac{\partial}{\partial x}\left[r \mu\left(2 \frac{\partial v_{x}}{\partial x}-\frac{2}{3}(\nabla \cdot \vec{v})\right)\right] \\
+\frac{1}{r} \frac{\partial}{\partial r}\left[r \mu\left(2 \frac{\partial v_{x}}{\partial r}+\frac{\partial v_{r}}{\partial x}\right)\right]+F_{x}
\end{array}
$$

Radial momentum:

$$
\begin{array}{r}
\frac{1}{r} \frac{\partial\left(r \rho v_{x} v_{r}\right)}{\partial x}+\frac{1}{r} \frac{\partial\left(r \rho v_{r} v_{r}\right)}{\partial r}= \\
-\frac{\partial p}{\partial r}+\frac{1}{r} \frac{\partial}{\partial x}\left[r \mu\left(\frac{\partial v_{r}}{\partial x}+\frac{\partial v_{x}}{\partial r}\right)\right]+ \\
\frac{1}{r} \frac{\partial}{\partial r}\left[r \mu\left(2 \frac{\partial v_{r}}{\partial r}-\frac{2}{3}(\nabla \cdot \vec{v})\right)\right] \\
-2 \mu \frac{v_{r}}{r^{2}}+\frac{2}{3} \frac{\mu}{r}(\nabla \cdot \vec{v})+F_{r}
\end{array}
$$


where

$$
\nabla \cdot \vec{v}=\frac{\partial v_{x}}{\partial x}+\frac{\partial v_{r}}{\partial r}+\frac{v_{r}}{r}
$$

Energy:

$$
\begin{gathered}
\nabla \cdot(\vec{v}(\rho E+p))= \\
\nabla \cdot\left(k_{e f f} \nabla T-\sum_{j} h_{j} \vec{J}_{j}+\left(\overline{\bar{\tau}}_{e f f} \cdot \vec{v}\right)\right)+S_{h}
\end{gathered}
$$

where $k_{e f f}$ is the effective conductivity and $\vec{J}_{j}$ is the diffusion flux of species $\mathrm{j}$. The terms on the right-hand side of equation (6) correspond to conduction, species diffusion, and viscous dissipation, respectively while $S_{h}$ is the source term due to the heat of chemical reaction.

In equation (6):

$$
E=h-\frac{p}{\rho}+\frac{v^{2}}{2}
$$

where sensible enthalpy $h$ is:

$$
h=\sum_{j} Y_{j} h_{j}
$$

where $Y_{j}$ is mass fraction of species $\mathrm{j}$, and $h_{j}$ is its specific enthalpy defined by:

$$
h_{j}=\int_{T_{r e f}}^{T} C_{p, j} d T
$$

The conservation equation for chemical species is:

$$
\frac{\partial}{\partial t}\left(\rho Y_{i}\right)+\nabla \cdot\left(\rho \vec{v} Y_{i}\right)=-\nabla \cdot \vec{J}_{j}+R_{i}+S_{i}
$$

where $R_{i}$ is the net rate of production by chemical reaction and $S_{i}$ is the rate of generation by addition form the dispersed phase. $\vec{J}_{j}$ is the diffusion flux of species $i$, which arises due to concentration gradients:

$$
\vec{J}_{j}=-\left(\rho D_{i, m}+\frac{\mu_{\mathrm{t}}}{\mathrm{Sc}_{\mathrm{t}}}\right) \nabla Y_{i}
$$

with $D_{i, m}$ being the laminar diffusion coefficient for species $i$ in the mixture and $\mathrm{Sc}_{\mathrm{t}}$ is the turbulent Schmidt number.

\section{B. Chemical Kinetics of Methane Combustion}

Reduced chemical mechanisms are used for the present simulation and two-step methane-air reaction is used as in equations. (11) and (12).

$$
\begin{gathered}
\mathrm{CH}_{4}+\frac{3}{2} \mathrm{O}_{2} \rightarrow \mathrm{CO}+2 \mathrm{H}_{2} \mathrm{O} \\
\mathrm{CO}+\frac{1}{2} \mathrm{O}_{2} \rightarrow \mathrm{CO}_{2}
\end{gathered}
$$

\section{C. $N O_{x}$ Formation}

Both thermal and prompt NOx formation mechanisms are considered in the present model. The extended Zeldovich mechanism is used to deal with the thermal $\mathrm{NO}_{\mathrm{x}}$ formation as seen below.

$$
\begin{aligned}
& O+N_{2} \leftrightarrow N+N O \\
& N+O_{2} \leftrightarrow O+N O
\end{aligned}
$$

$$
\mathrm{N}+\mathrm{OH} \leftrightarrow \mathrm{NO}+\mathrm{H}
$$

The formation rate of $\mathrm{NO}_{\mathrm{x}}$ is significant only at high temperatures corresponding to high required activation energy of reaction in (13). Due to the existence of the ' $\mathrm{O}$ ' radical in turbulent diffusion flames [15] its concentration is determined by partial equilibrium approximation. The prompt $\mathrm{NO}_{\mathrm{x}}$ is considered with the following reactions:

$$
\begin{aligned}
& \mathrm{CH}+\mathrm{N}_{2} \leftrightarrow \mathrm{HCN}+\mathrm{N} \\
& \mathrm{N}+\mathrm{CH}_{3} \leftrightarrow \mathrm{HCN}+\mathrm{N}_{2} \\
& \mathrm{HCN}+\mathrm{O} \leftrightarrow \mathrm{NCO}+\mathrm{H} \\
& \mathrm{HCN}+\mathrm{O} \leftrightarrow \mathrm{NH}+\mathrm{CO} \\
& \mathrm{HCN}+\mathrm{OH} \leftrightarrow \mathrm{CN}+\mathrm{H}_{2} \mathrm{O} \\
& \mathrm{NH}+\mathrm{H} \leftrightarrow \mathrm{N}+\mathrm{H}_{2}
\end{aligned}
$$

\section{Radiation Model}

Discrete Ordinate (DO) method is used for radiation consideration and is given by:

$$
\begin{gathered}
\frac{d I(\vec{r}, \vec{s})}{d s}+\left(a+\sigma_{s}\right) I(\vec{r}, \vec{s})=a n^{2} \frac{\sigma T^{4}}{\pi}+ \\
\frac{\sigma_{s}}{4 \pi} \int_{0}^{4 \pi} I(\vec{r}, \vec{\zeta}) \Phi(\vec{s}, \vec{\zeta}) d \Omega^{\prime}
\end{gathered}
$$

where $\vec{r}, \vec{s}$ and $\vec{\zeta}$ represent vectors of position, direction and scattering vectors respectively, and $\sigma_{s}, a, I, \mathrm{~T}, \Phi$ and $\Omega^{\prime}$ denote scattering coefficient, absorption coefficient, radiation intensity, local temperature, phase function and solid angle respectively.

\section{RESUlTS AND DISCUSSION}

Figure 2 shows the temperature gradient for the homogeneous layer $\varepsilon=0.6$ (a) , addition of a second layer downstream $\varepsilon=0.45$ dividing the porous zone into two layers of equal height (b) and further height variation where the height of the $\varepsilon=0.6$ layer is decreased while $\varepsilon=0.45$ is increased (c). Methane and air, 0.23 oxygen mass fraction, are injected into the domain with $v=0.01 \mathrm{~m} / \mathrm{s}$ through the fuel nozzle and annulus, respectively. Solid and gas are assumed to be in thermal equilibrium and burner to be perfectly insulated. The temperature gradient is shown to increase, while the combustion zone to decrease with addition of a second layer in 


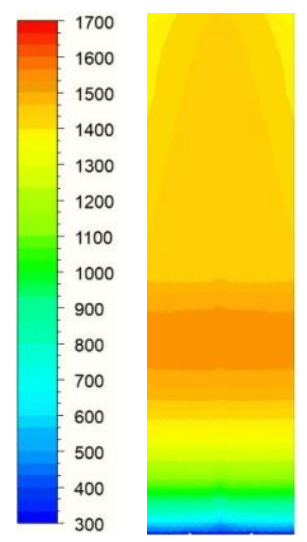

${ }^{\mathrm{o}} \mathrm{K}$

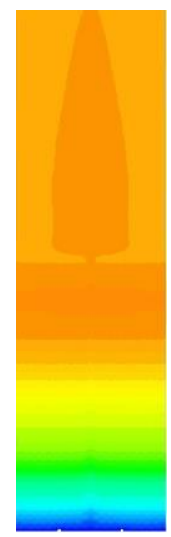

(b)

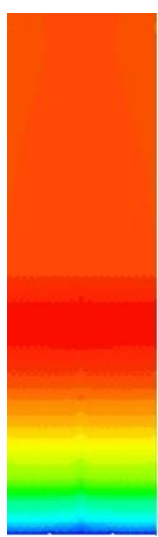

(c)

Figure 2. Temperature distribution (a) Single layer $\varepsilon=0.6$ (b) Double layer $\varepsilon=0.6$ and 0.45 (c) Double layer $\mathrm{h}=37.5 \mathrm{~mm}$ for $\varepsilon=0.6$ and $\mathrm{h}=112.5 \mathrm{~mm}$ for $\varepsilon=0.45$

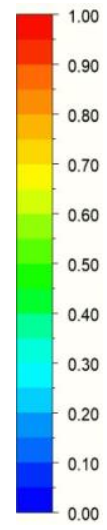

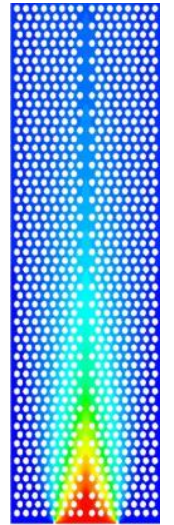

(a)

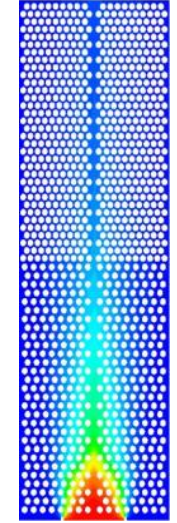

(b)

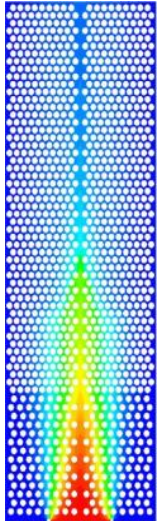

(c)

Figure 3. Porous zone methane mass fraction (a) Single layer $\varepsilon=0.6$ (b) Double layer $\varepsilon=0.6$ and 0.45 (c) Double layer $h=37.5 \mathrm{~mm}$ for $\varepsilon=0.6$ and $\mathrm{h}=112.5 \mathrm{~mm}$ for $\varepsilon=0.45$

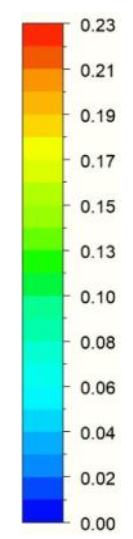

(a)

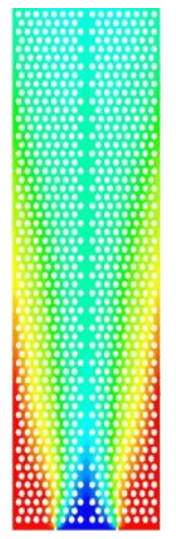

(b)

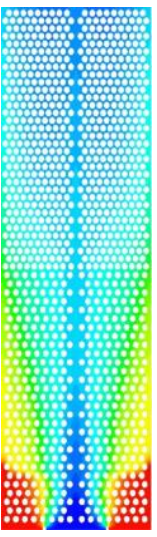

(c)

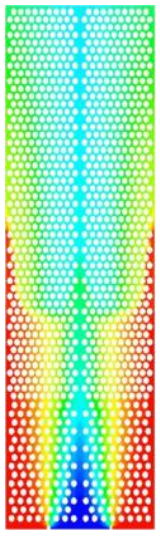

Figure 4. Porous zone oxygen mass fraction (a) Single layer $\varepsilon=0.6$ (b) Double layer $\varepsilon=0.6$ and 0.45 (c) Double layer $h=37.5 \mathrm{~mm}$ for $\varepsilon=0.6$ and $\mathrm{h}=112.5 \mathrm{~mm}$ for $\varepsilon=0.45$ (b) and further increase with the increased height of the downstream layer $\varepsilon=0.45$ as seen in (c). This can be attributed to the combined effects of conduction and radiation heat transfer within the solid matrix, where the incoming reactants are preheated, combined with the increased surface area and decreased porosity of the downstream layer consequently yielding higher temperature. Figure 2 (a) and (b) show a conical flame outside of the porous zone, which is consistent to that of a diffusion flame as outlined in [14] meanwhile the lack of such flame in Figure 2 (c) can be attributed to the higher amount of methane present in the downstream region of the layered porous media and above in the free zone as seen in Figure 3. Furthermore, temperature increase in the porous zone with an additional layer (b) and further increase with height decrease of the higher porosity layer (c) indicates that the gas mixture velocity is increased, and the mixture is accelerated within the porous media.

Figure 3 illustrates methane mass fraction in the porous zone. From the figure it is evident that the lowest methane concentration distribution is exhibited in (b) while the highest in (c). Similarly, lowest oxygen concentration distribution, as seen in Figure 4, corresponds to (b) as well. The aforementioned figures show that the reactant mixing is facilitated by insertion of the second layer, however variation in layer height, where height of the downstream lower porosity layer is increased has the opposite effect. The decreased reactant mixing in the porous zone as shown Figures 3 and 4 (c) can be attributed to the increased gas velocity, where combustion occurs in a narrower region and higher temperature further downstream as seen in Figure 2 (c). It should be noted that the outlined results are specific to the model geometry where the given alumina sphere arrangement is not uniform in the middle of the computational domain.

Nitrogen oxides emission depends on oxygen concentration and temperature where high oxygen concentration and temperature hot spots yield higher $\mathrm{NO}_{\mathrm{x}}$. Nitrogen oxide emission reduction strategies involve reducing the combustion temperature, oxygen concentration and residence time at high temperatures. Figure 5 shows the NO mass fraction along the symmetry axis of the computational domain. With lower combustion temperature and oxygen concentration, evenly spaced double layer arrangement produced the lowest NO emission. The thermal $\mathrm{NO}_{\mathrm{x}}$ depends on the mechanisms in which the nitrogen combines with oxygen to produce $\mathrm{NO}_{\mathrm{x}}$. These mechanisms (Equations 13-21) have high activation energy barrier and they are activated in high temperature zones. This is evident with the altered height double layer arrangement as the NO emission is higher than that of equal height layer arrangement. 


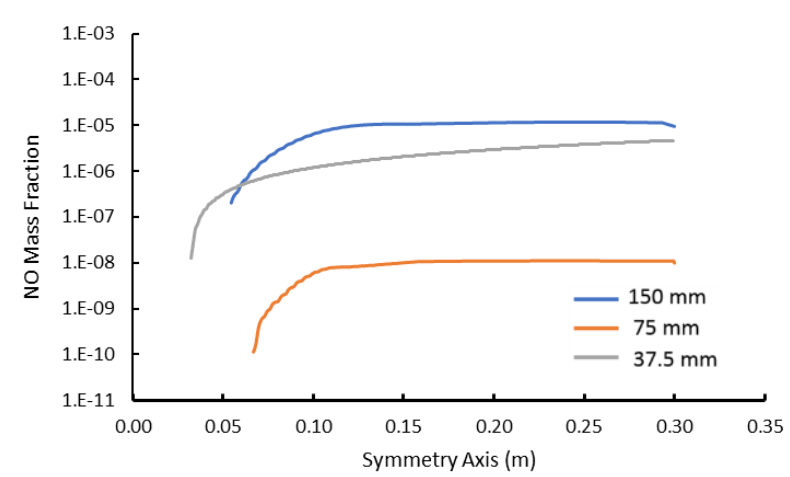

Figure 5. NO mass fraction along the symmetry axis, based on $\varepsilon=0.6$ layer height.

\section{CONCLUSION}

Numerical investigation on the effects of double layer porous media and layer height variation on diffusion filtration combustion is presented. The primary focus of this study is to investigate the effect of double layer porous media height variation on reactant mixing and consequent combustion temperature and NOx emission A homogenous packed bed of $\varepsilon=0.6$ porosity is used as a baseline to which another layer of $\varepsilon=0.45$ is added downstream within the PM. The height of each layer is then varied, and the effects of each variation on diffusion filtration combustion are recorded. Results indicate that insertion of a second layer of equal height and lower porosity in the downstream region of the porous media improved reactant mixing yielding higher combustion temperature, decreased combustion zone and lower NOx emission. Additionally, increasing the height of the lower porosity downstream region resulted in further combustion temperature increase and combustion zone decrease with an increase in NOx emission. It can be concluded that utilizing multi-layered porous media can improve combustion efficiency.

\section{REFERENCES}

[1] T. Takeno and K. Sato, "An Excess Enthalpy Flame Theory,” Combust. Sci. Technol., vol. 20, no. 1-2, pp. 73-84, 1979

[2] M. A. Mujeebu, M. Z. Abdullah, A. A. Mohamad, and M. Z. A. Bakar, "Trends in modeling of porous media combustion," Progress in Energy and Combustion Science, vol. 36, no. 6. pp. 627-650, 2010.

[3] K. Kamiuto and S. Miyamoto, "Diffusion flames in plane-parallel packed beds," Int. J. Heat Mass Transf., vol. 47, no. 21, pp. 4593-4599, 2004.

[4] A.A.Mohamad, "11 - Combustion in porous media: Fundamentals and applications," in Transport Phenomena in Porous Media III, 2005, pp. 287-304.

[5] M. M. Kamal and A. A. Mohamad, "Combustion in porous media," Proc. Inst. Mech. Eng. Part A J. Power Energy, 2006.

[6] W. S. Harris A, "Porous burners for lean-burn applications," Prog. Energy Combust. Sci, vol. 34, pp. 667-684, 2008

[7] M. Z. A. B. M. Abdul Mujeebu, M. Z. Abdullah, and A. A. Mohamad, "Trends in modeling of porous media combustion," Prog. Energy Combust. Sci, vol. 36, pp. 627-650, 2010.

[8] K. K. and T.Ogawa, "Diffusion Flames in Cylindrical Packed Beds," $J$. Thermodyn. Heat Transf., vol. 11, no. 4, pp. 585-587, 1997.

[9] K. V. Dobrego, I. M. Kozlov, S. A. Zhdanok, and N. N. Gnesdilov, "Modeling of diffusion filtration combustion radiative burner," Int. J. Heat Mass Transf., vol. 44, no. 17, pp. 3265-3272, 2001.

[10] M. M. Kamal and A. A. Mohamad, "Enhanced radiation output from foam burners operating with a nonpremixed flame," Combust. Flame, vol. 140, no. 3, pp. 233-248, 2005.

[11] J. Zhang, L. Cheng, C. Zheng, Z. Luo, and M. Ni, "Development of nonpremixed porous inserted regenerative thermal oxidizer," J. Zhejiang Univ. Sci. A, vol. 14, no. 9, pp. 671-678, 2013.

[12] S. S. Kostenko, A. N. Ivanova, A. A. Karnaukh, and E. V. Polianczyk, "Conversion of methane to synthesis gas in a non-premixed reversed-flow porous bed reactor: A kinetic modeling," Chem. Eng. Process. Process Intensif., vol. 122, no. December 2016, pp. 473-486, 2017.

[13] J. R. Shi, B. W. Li, Li-Nan, Y. F. Xia, Y. N. Xu, and H. S. Liu, "Experimental and numerical investigations on diffusion filtration combustion in a plane-parallel packed bed with different packed bed heights," Appl. Therm. Eng., vol. 127, pp. 245-255, 2017

[14] H. Li, J. Shi, M. Mao, and Y. Liu, "Experimental and numerical studies on combustion characteristics of N2-diluted $\mathrm{CH} 4$ and $\mathrm{O} 2$ diffusion combustion in a packed bed," R. Soc. Open Sci., vol. 6, no. 9, 2019.

[15] R. W. V. Dupont, M. Pourkashanian, A. Williams, "The reduction of NOx formation in natural gas burner flames," Fuel, vol. 72, pp. 497-503, 1993. 